\title{
Quality control and characterization of the testicles and ovaries of irradiated Anastrepha
}

\section{obliqua from Brazil}

\author{
Karen Zamboni Costa๑, Maria Lourdes Zamboni Costa๑, Victor Wilson Botteon*®, Kenya Martins Faggioni๑, Neivaldo Costa๑, \\ Thiago Mastrangelo॰
}

Universidade de São Paulo/CENA, Lab. de Radioentomologia e Irradiação de Alimentos, Av. Centenário, 303 - 13416-000

- Piracicaba, SP - Brasil.

${ }^{*}$ Corresponding author <victor_botteon2@hotmail.com>

Edited by: Richard V. Glatz

Received July 21, 2017

Accepted July 17, 2018
ABSTRACT: With the aim of making the application of the Sterile Insect Technique (SIT) feasible in the management of the West Indian fruit fly in Brazil, Anastrepha obliqua (Macquart) (Diptera: Tephritidae), a number of quality parameters required by the SIT were investigated in this study. The aim was to verify the influence of a range of doses of gamma radiation $(40,50,60,70$ and $80 \mathrm{~Gy}$ ) on the fertility of females and to evaluate several quality control parameters, such as fly emergence, sex ratio, flight ability and survival under stress, as well as the characterization of the morphology (measurement of length and width) of the ovaries and testicles of $A$. obliqua. Pupae with $24 \mathrm{~h}$ before adult emergence were irradiated at CENA/Universidade de São Paulo. The radiosterilization test showed no difference between treatments for the parameters of fly emergence, sex ratio and survival under stress. The radiation at doses above 40 Gy resulted in ovarian atrophy in females and the absence of egg production. In males, the radiation also affected testicular development. Considering the quality parameters assessed, the sterilization results obtained agreed with previous data in the literature for other $A$. obliqua strains, and the dose of 60 Gy could be considered as the best compromise between insect quality and full sterility for the Brazilian strain of $A$. obliqua evaluated.

Keywords: Sterile Insect Technique, West Indian fruit fly, radiosterilization, ovarian atrophy, flight ability

\section{Introduction}

The fruit flies of the genus Anastrepha Schiner (1868) (Diptera: Tephritidae) cause great damage to fruit production in America (Malavasi and Zucchi, 2000). In Brazil one of the least studied species of economic and quarantine importance is the West Indian fruit fly, Anastrepha obliqua Macquart, found in almost all states, especially in Amazonas and Maranhão, with approximately 70 registered hosts (Fu et al., 2014).

In Mexico, A. obliqua populations have been suppressed by the Sterile Insect Technique (SIT) since the early 1990's. The mass-rearing of sterile flies at the Moscafrut Fruit Fly Facility began at the end of 1995, and 65 million sterile $A$. obliqua were produced per week in 2015 (Orozco-Dávila et al., 2017).

Because of the existing variabilities between populations of $A$. obliqua and the presumed existence of a group of cryptic species (Ruíz-Arce et al., 2012; SmithCaldas et al., 2001), the study of Brazilian populations is extremely relevant to pest management. Castañeda et al. (2015) showed significant morphological differentiation between South American populations of A. obliqua, including comparisons between Brazilian populations, demonstrating the importance of studies with different strains of $A$. obliqua in different regions. To date, there are no studies of radiosterilization of $A$. obliqua Brazilian strains.

In this context, quality control aims to provide quality and sterility assurance for individuals to be released in the field and to be put on alert for operational deficiencies (Dominiak et al., 2014). Since 1997, for example, the FAO/IAEA/USDA has provided a set of standards for assessing the quality of sterile fruit flies used in SIT programs (FAO, 2003). Studies of radiosterilization in $A$. obliqua assessing biological parameters are very scarce, and have been carried out mainly on Mexican strains (Gallardo-Ortiz et. al., 2018; Orozco-Dávila et al., 2017; Rull et al., 2012; Toledo et al., 1993, 2004). More information on quality control of irradiated individuals is necessary before encouraging the application of a SIT program against this pest in Brazil. Furthermore, there were no studies of the effects on testicles and ovaries of a laboratory strain of $A$. obliqua exposed to gamma radiation.

Therefore, the aim of this study was to determine the effects of gamma radiation doses on a Brazilian strain of $A$. obliqua in order to generate relevant data that could be useful for the eventual implementation of SIT against this pest in Brazil.

\section{Materials and Methods}

The study was conducted at CENA/Universidade de São Paulo, Piracicaba, in the state of São Paulo, Brazil. The domestication of $A$. obliqua and rearing followed the methodology proposed by Walder et al. (2014) for A. fraterculus. Adults of $A$. obliqua came from pupae obtained from infested star fruits collected in the municipality of Piracicaba. The larvae were reared on papaya up to the $6^{\text {th }}$ generation. From the $7^{\text {th }}$ generation onwards, the larvae started to feed on an artificial diet. The 
A. obliqua individuals used for the experiments were obtained from the $17^{\text {th }}$ generation of the colony.

The $A$. obliqua larvae of this colony were reared using an artificial diet based on Salles (1992): wheat germ, brewer's yeast, sugar, hydrochloric acid, sodium benzoate, $10 \%$ nipagin, agar and water. Larvae were collected on the $10^{\text {th }}$ day by washing the diet on a sieve, after they began to crawl from the diet, allowed to pupate on moistened vermiculite and kept in a controlled environment room $\left(25 \pm 1{ }^{\circ} \mathrm{C}, 65 \pm 5 \% \mathrm{RH}\right.$ and external lighting of 10,000 lux with a photoperiod of 10:14 [L:D] h).

\section{Irradiation settings}

The source of radiation was a ${ }^{60} \mathrm{Co}$ irradiator with a dose rate of $7.8 \mathrm{~Gy} / \mathrm{min}$ at the beginning of the tests. The radiosterilization test was performed with pupae $24 \mathrm{~h}$ before adult emergence treated with the following gamma radiation doses ( ${ }^{60} \mathrm{Co}$ ): 0 (control), 40, 50, 60, 70 and 80 Gy. All irradiations were carried out in separate assays with three pupal cohorts (one cohort per generation) and performed under normal atmospheric conditions (free oxygen). For each irradiation, dosimetry was performed with a Fricke Dosimeter (Fricke and Hart, 1966).

\section{Radiosterilization tests and biological dosimetry}

After irradiation, for each treatment, samples, each consisting of 50 pupae, were separated from the batches and placed in $500 \mathrm{~mL}$ plastic pots to determine the emergence percentage and sex ratio $[\mathrm{sr}=q / 1 \hat{0}+$ q)], quantified after $72 \mathrm{~h}$. Five replicates were performed per treatment in time using different pupal cohorts.

Pupae from each treatment were kept in appropriate cages until emergence. The adults were fed ad libitum with a mixture of hydrolyzed yeast, raw wheat germ and sugar (1:1:3) and water was supplied in Petri dishes with cotton. Three days after emergence, 10 males and 10 females were separated and placed in $1.5 \mathrm{~L}$ plastic pots ('mini-cages') with a screened upper part for ventilation and a voile coated with a thin layer $(0.1 \mathrm{~mm})$ of silicon installed for oviposition.

For each treatment, the following groups were formed: 10 irradiated males (doses of 40, 50, 60, 70 and $80 \mathrm{~Gy}) \times 10$ non-irradiated females $(0 \mathrm{~Gy}), 10$ non-irradiated males $(0 \mathrm{~Gy}) \times 10$ irradiated females (doses of 40 , $50,60,70$ and $80 \mathrm{~Gy})$; and 10 non-irradiated males $\times 10$ non-irradiated females for control. Five replicates were performed per treatment.

After reaching sexual maturity ( 8 to 10 days after adult emergence), egg samples were collected daily for 10 consecutive days. The eggs were counted and arranged on filter paper moistened within a Petri dish and incubated at $25 \pm 1{ }^{\circ} \mathrm{C}$ for 4 days. After this period, the number of empty chorions was counted and egg hatch (\%) was calculated by the following formula: [/number of empty chorions $\times 100$ /total number of eggs collected]. The egg collection was maintained until at least 1,000 eggs were obtained in each treatment. Ten repli- cates were performed for each treatment. The number of eggs/day/female was recorded for each treatment in order to estimate fecundity.

\section{Flight Ability of irradiated Anastrepha obliqua}

The flying ability of irradiated adults of $A$. obliqua was assessed by placing 50 pupae from each treatment ( $24 \mathrm{~h}$ before adult emergence) into a paper ring approximately $5.0 \mathrm{~cm}$ in diameter $\times 0.5 \mathrm{~cm}$, centered in a Petri dish measuring $10.0 \mathrm{~cm}$ in diameter, coated with filter paper. A black plastic tube measuring $12.0 \mathrm{~cm}$ in diameter $\times 12.0 \mathrm{~cm}$ in height was attached to the interior of the Petri dish. The inner part of the tube was coated with unscented talcum powder, approximately $1.0 \mathrm{~cm}$ above the bottom of the tube. Talcum powder was used to prevent flies from escaping by walking away. The black tubes were placed on a table in an enclosed and controlled environment room.

After emergence, the fruit flies were stimulated to fly while keeping the lights on. After 72 hours, the individuals (deformed, non-emerged, flying and non-flying flies) remaining (dead and/or alive) in the tubes were recorded to assess the percentage of flies that were not able to fly (FAO, 2003, 2014). The rate of flying flies (\%) was calculated using the formula: $\{100 \times$ [total pupae - (non-flying flies + non-viable pupae + deformed flies + partially emerged flies)] / total pupae\}. Five replicates were performed per treatment.

\section{Survival under stress for irradiated Anastrepha obliqua}

For each treatment (doses of 0,40,50,60, 70 and $80 \mathrm{~Gy})$, the survival of adults under stress conditions was determined by the confinement of 10 males and 10 females, newly emerged, into $500 \mathrm{~mL}$ plastic pots without food and water. Flies were kept in a controlled environment room $\left(25 \pm 1{ }^{\circ} \mathrm{C}, 65 \pm 5 \% \mathrm{RH}\right.$ and photoperiod of 10:14 [L:D] h). Survival was recorded at 72 and $96 \mathrm{~h}$. Five replicates were performed per treatment in time with pupae from the three different cohorts.

\section{Effect of radiation on ovaries and testicles of Anastrepha obliqua}

To evaluate the effect of radiation on gonadal development, 20 males and females for each dose were separated after emergence in individual cages and kept virgin for 9 days. After this period, the flies were decapitated and dissected in a saline solution $(0.85 \% \mathrm{NaCl}$ solution). Testicles and ovaries were measured to evaluate the effects of irradiation on the development of these organs.

After removal of the reproductive system using magnification lenses (10x to $30 \mathrm{x})$ and extra fine-tipped tweezers, the testicles and ovaries were transferred to a clean microscope slide and examined as whole mounts through a digital micrometer coupled to a stereoscopic microscope. The length $(\mathrm{mm})$ and width $(\mathrm{mm})$ of each testicle and ovary were measured with a scale (40 testicles and 40 ovaries per treatment). 


\section{Statistical analysis}

The analyses were performed by the statistical program SAS (Statistical Analysis System, version 9.1). For statistical analysis of sterility, Probit regression following Sokal \& Rohlf (1981) was performed. The results of sex ratio, emergence, longevity under stress, flying ability and, for the testicles and ovaries, measurements were submitted to a one-way analysis of variance F-test at $5 \%$ significance (ANOVA) and Tukey's honestly significant difference (HSD) test $(\alpha=5 \%)$ was applied to compare the means, when a significant difference was found. The Bartlett and Shapiro-Wilk tests were performed to verify the homoscedasticity assumptions and the normality of the errors, respectively.

\section{Results}

None of the dosimetry results differed at the $5 \%$ level from the target dose. The overall $95 \%$ confidence interval for doses measured by the Fricke dosimeters was $\pm 2.8 \%$. The target dose values were, therefore, used throughout the analyses.

The dose that resulted in greater sterilization of males was 80 Gy (99.7\% sterility). No eggs were produced in the treatments where non-irradiated males were crossed with irradiated females. The fecundity of $A$. obliqua irradiated males crossed with non-irradiated females is shown in Table $1\left(\mathrm{~F}_{5,29}=0.91, p=0.4939\right.$, C.V. $=9.8 \% ; \mathrm{F}_{1,4}=3.10 ; p=0.17$, respectively). The fertility of males irradiated with 80 Gy was only $0.31 \pm$ $0.12 \%$, while in the control the mean egg hatch was 66 $\pm 0.46 \%$. According to the probit regression obtained for the irradiated males (Figure 1), the dose required inducing $99 \%$ sterility $\left(\mathrm{D}_{99}\right)$ in A. obliqua males was estimated at $55.4 \mathrm{~Gy}$, with upper and lower confidence limits (95\%) estimated at $87.03 \mathrm{~Gy}$ and $35.3 \mathrm{~Gy}$, respectively. The $\mathrm{D}_{50}$, for instance, was estimated at 32.6 Gy $(95 \%$ confidence interval $=10.4-101.8 \mathrm{~Gy})$ and the $\mathrm{D}_{90}$ was $43.6 \mathrm{~Gy}(95 \%$ confidence interval $=22.01$ - 86.5 Gy).

The percentage of fly emergence and sex ratio of A. obliqua were not affected by the doses of radiation

Table 1 - Mean fecundity and sterility ( \pm SE) of Anastrepha obliqua irradiated with different doses of gamma radiation at the pupal stage, $24 \mathrm{~h}$ before adult emergence.

\begin{tabular}{lcc}
\hline Doses & Total number of eggs collected & Fecundity \\
\hline Gy & & number of eggs/ day / 9 \\
0 & 2620 & $52.4 \pm 9.10$ \\
40 & 2891 & $57.8 \pm 12.74$ \\
50 & 3158 & $63.1 \pm 9.25$ \\
60 & 2196 & $43.9 \pm 7.42$ \\
70 & 3229 & $64.5 \pm 11.69$ \\
80 & 2122 & $42.4 \pm 3.96$ \\
\hline & ANOVA* \\
\hline & & $\mathrm{F}_{5,29}=0.9 ; p=0.5 ;$ C.V. $=9.9$ \\
\hline
\end{tabular}

${ }^{*}$ Mean fecundity values did not differ significantly (ANOVA; $p>0.05$ ).
$\left(\mathrm{F}_{5,29}=2.11, p=0.09, \mathrm{C} . \mathrm{V} .=3.4 \% ; \mathrm{F}_{5,29}=0.49, p\right.$ $=0.77, \mathrm{C} . \mathrm{V} .=5.3 \%$, respectively) (Table 2). These results indicate that up to $80 \mathrm{~Gy}$, the radiation did not negatively affect these quality control parameters under laboratory conditions.

Table 3 shows the mean values of male and female survival under stress and percentage of fliers. The mean survival under stress of $A$. obliqua males and females from irradiated pupae ( $24 \mathrm{~h}$ before emergence) was not affected by the different doses after $72 \mathrm{~h}\left(\mathrm{~F}_{5,29}\right.$ $=0.48, p=0.7871, \mathrm{C} . \mathrm{V} .=6.4 \% ; \mathrm{F}_{5,29}=1.38, p=$ 0.2683 , C.V. $=9.5 \%$ for males and females, respectively). After $96 \mathrm{~h}$, all the flies died in all treatments.

Significant differences were observed in flying ability $\left(\mathrm{F}_{5,29}=3.19, p=0.02, \mathrm{C} . \mathrm{V} .=2.6 \%\right)$ (Table 3). The insects irradiated with the dose of $40 \mathrm{~Gy}$ had a higher percentage of fliers, differing from the insects that were exposed to the highest dose of gamma radiation (80 Gy).

The effects of gamma radiation on the length and width of testicles and ovaries of $A$. obliqua are presented in Table 4, Figure 2 and Figure 3. The length and width of the ovaries from the flies irradiated with 40 Gy or higher did not differ significantly between them, but they differed significantly from the means of the

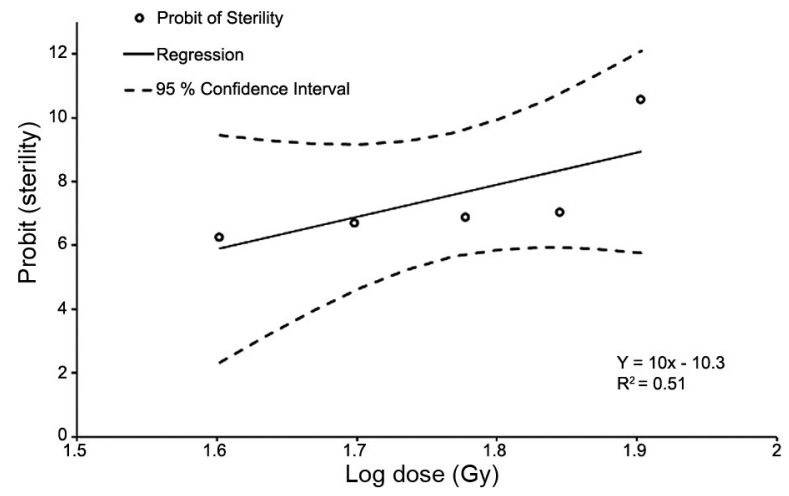

Figure 1 - Linear regression of Probit transformed sterility on log dose for males of Anastrepha obliqua irradiated as pupae $24 \mathrm{~h}$ before adult emergence.

Table 2 - Means ( \pm SE) of emergence of flies and sex ratio of Anastrepha obliqua irradiated with different doses of gamma radiation at the pupal stage, $24 \mathrm{~h}$ before adult emergence.

\begin{tabular}{lcc}
\hline Doses & Fly Emergence & Sex Ratio \\
\hline Gy & $\%$ & $+/ \widehat{\jmath}+q$ \\
0 & $91.2 \pm 1.36$ & $0.47 \pm 0.07$ \\
40 & $96.0 \pm 0.89$ & $0.45 \pm 0.07$ \\
50 & $94.0 \pm 0.89$ & $0.46 \pm 0.04$ \\
60 & $90.4 \pm 2.32$ & $0.43 \pm 0.08$ \\
70 & $94.0 \pm 1.67$ & $0.45 \pm 0.05$ \\
80 & $92.4 \pm 0.75$ & $0.40 \pm 0.10$ \\
\hline ANOVA $^{*}$ & $\mathrm{~F}_{5,29}=2.11 ; p=0.09 ;$ & $\mathrm{F}_{5,29}=0.49 ; p=0.77 ;$ \\
C.V. $=3.38$ & $=5.28$ \\
\hline${ }^{*}$ Means $( \pm \mathrm{SE}$ ) in the columns did not differ significantly (ANOVA $; p>0.05)$.
\end{tabular}


Table 3 - Mean survival ( \pm SE) under stress of males and females after $72 \mathrm{~h}$ and flight ability of Anastrepha obliqua irradiated with different doses of gamma radiation at the pupal stage, $24 \mathrm{~h}$ before adult emergence.

\begin{tabular}{|c|c|c|c|}
\hline \multirow{2}{*}{ Treatment } & \multicolumn{2}{|c|}{ Mean survival \pm SE $(\%)$} & \multirow{2}{*}{ Flying flies } \\
\hline & 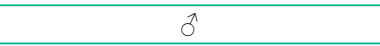 & 운 & \\
\hline Gy & 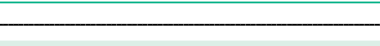 & 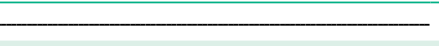 & $\%$ \\
\hline 0 & $50 \pm 4.47 a^{*}$ & $66 \pm 7.48 a$ & $70.0 \pm 3.03 a b$ \\
\hline 40 & $52 \pm 7.35 \mathrm{a}$ & $52 \pm 4.90 \mathrm{a}$ & $76.4 \pm 2.48 a$ \\
\hline 50 & $50 \pm 3.16 a$ & $50 \pm 4.47 a$ & $70.8 \pm 1.62 a b$ \\
\hline 60 & $56 \pm 5.10 a$ & $56 \pm 6.0 \mathrm{a}$ & $72.4 \pm 1.33 a b$ \\
\hline 70 & $46 \pm 5.10 a$ & $42 \pm 8.60 \mathrm{a}$ & $69.2 \pm 1.85 a b$ \\
\hline 80 & $46 \pm 5.10 a$ & $46 \pm 5.10 a$ & $65.6 \pm 0.98 b$ \\
\hline ANOVA & $F_{5,29}=0.48 ; p=0.78 ; C . V .=6.4$ & $F_{5,29}=1.38 ; p=0.26 ; C . V .=9.5$ & $F_{5,29}=3.19 ; p=0.02 ;$ C.V. $=2.62$ \\
\hline
\end{tabular}

${ }^{*}$ Means $( \pm$ SE) followed by the same letters in the columns do not differ significantly by Tukey's test $(p>0.05)$.

Table 4 - Mean length and width $(\mathrm{mm})$ of testicles and ovaries of 9 day old Anastrepha obliqua submitted to different doses of gamma radiation.

\begin{tabular}{|c|c|c|c|c|}
\hline \multirow{2}{*}{ Treatment } & \multicolumn{2}{|c|}{ Testicles } & \multicolumn{2}{|c|}{ Ovaries } \\
\hline & Mean lenght \pm SE & Mean width \pm SE & Mean lenght \pm SE & Mean width \pm SE \\
\hline Gy & & & & \\
\hline 0 & $0.784 \pm 0.017 a^{*}$ & $0.304 \pm 0.006 a$ & $2.016 \pm 0.038 a$ & $1.317 \pm 0.048 a$ \\
\hline 40 & $0.683 \pm 0.017 b$ & $0.249 \pm 0.004 b$ & $0.688 \pm 0.016 b$ & $0.301 \pm 0.008 b$ \\
\hline 50 & $0.720 \pm 0.020 a b$ & $0.264 \pm 0.006 b$ & $0.652 \pm 0.017 b c$ & $0.299 \pm 0.007 b$ \\
\hline 60 & $0.718 \pm 0.020 \mathrm{ab}$ & $0.255 \pm 0.005 b$ & $0.694 \pm 0.016 b$ & $0.302 \pm 0.006 b$ \\
\hline 70 & $0.692 \pm 0.015 b$ & $0.253 \pm 0.004 b$ & $0.657 \pm 0.017 b c$ & $0.308 \pm 0.006 b$ \\
\hline 80 & $0.718 \pm 0.022 a b$ & $0.264 \pm 0.005 b$ & $0.606 \pm 0.020 c$ & $0.299 \pm 0.019 b$ \\
\hline ANOVA & $\begin{array}{c}\mathrm{F}_{5,235}=3.23 ; p=0.007 \\
\text { C.V. }=6.74\end{array}$ & $\begin{array}{c}\mathrm{F}_{5,235}=16.48 ; p<10^{-3} ; \\
\text { C.V. }=2.48\end{array}$ & $\begin{array}{c}\mathrm{F}_{5,238}=483.96 ; p<10^{-3} \\
\text { C.V. }=11.55\end{array}$ & $\begin{array}{c}\mathrm{F}_{5,239}=531.40 ; p<10^{-3} \\
\text { C.V. }=17.85\end{array}$ \\
\hline
\end{tabular}

${ }^{*}$ Means ( \pm SE) followed by the same letters in the columns do not differ significantly by Tukey's test $(p>0.05)$.

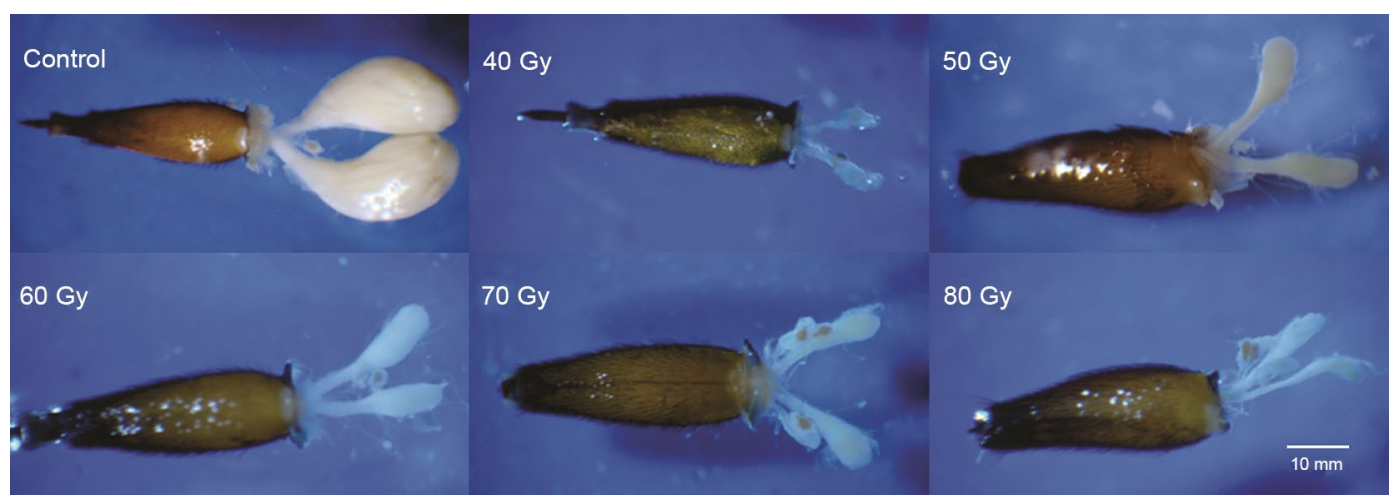

Figure 2 - Comparison in ovarian development of Anastrepha obliqua (9 days-old) irradiated as pupae with different doses of gamma radiation.

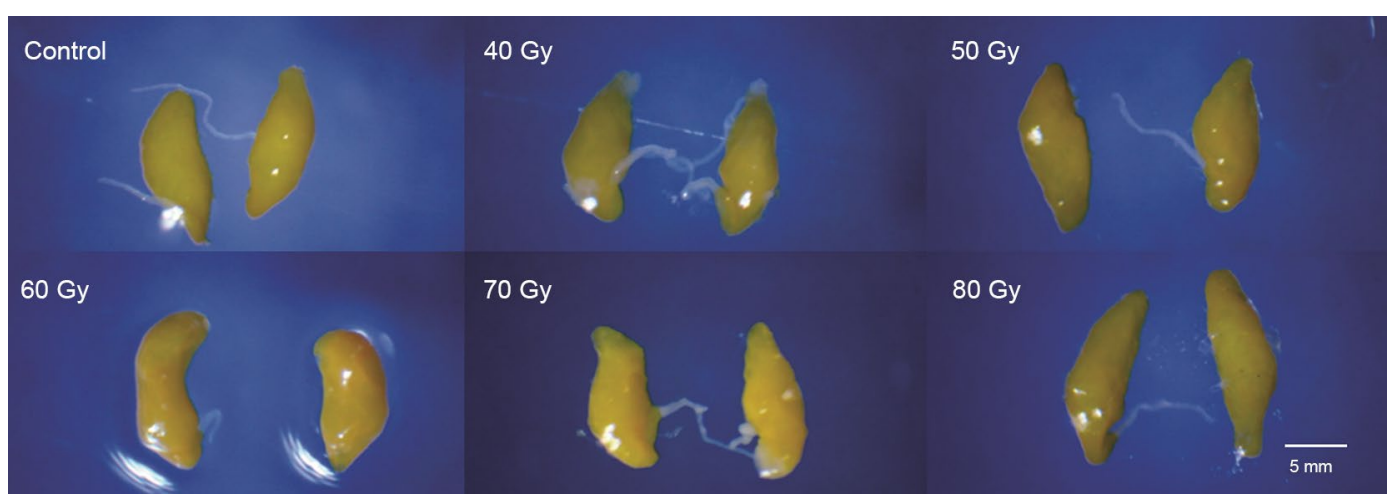

Figure 3 - Comparison in testicle development of Anastrepha obliqua (9 days-old) irradiated as pupae with different doses of gamma radiation. 
control group (length: $\mathrm{F}_{5,238}=483.96, p<0.001, \mathrm{C} . \mathrm{V}$. $=11.5 \%$; width: $\mathrm{F}_{5,239}=531.40, p<0.001, \mathrm{C} . \mathrm{V}$. $=$ $17.8 \%)$. Testicular development was also affected by irradiation, but less pronounced than the ovaries. The length and the width of most of the irradiated testicles were significantly lower than in the control $\left(\mathrm{F}_{5,235}=\right.$ $3.23 ; p=0.007 ;$ C.V. $=6.7 \% ; \mathrm{F}_{5,235}=16.48 ; p<0.001$; C.V. $=2.5 \%)$.

\section{Discussion}

Rearing conditions and standardized quality control are essential to guaranteeing the success and applicability of SIT programs (Calkins and Parker, 2005; Hendrichs et al., 2002; Parker, 2005; Rull et al., 2012). In this context, the sterilization process and maintenance of accurate quality control in all steps are fundamental to maintaining the performance of the sterile males in the field (Cáceres et al., 2014; Rull et al., 2012).

In studies referring to sterility in males of the genus Anastrepha, the sterilization dose differs with respect to species. For example, Walder and Calkins (1992) found that 50 Gy caused total sterility in A. suspensa (Loew). Rull et al. (2007) reported that doses of 40-80 Gy provoked $95 \%$ sterility in A. ludens (Loew). Allinghi et al. (2007) and Mastrangelo et al. (2010) observed that doses higher than 35-40 Gy can induce 99 $\%$ sterility in $A$. fraterculus (Wiedemann). According to Toledo (1993) the radiation dose of 80 Gy caused 100 $\%$ of sterility on wild $A$. obliqua collected on infested Mexican mombin fruit (Spondias mombin L.).

In the case of $A$. obliqua, many studies have found that increasing doses of radiation can negatively affect a number of its quality parameters (Gallardo-Ortiz et al., 2018; Rull et al., 2012; Toledo et al., 2004), which is inconvenient for SIT application. As male competitiveness can be affected by the doses required to attain full sterility (Fisher, 1997), Toledo et al. (2004) suggested that the radiation doses for $A$. obliqua should be between 50 and $75 \mathrm{~Gy}$. These authors also observed a decreasing trend in adult flying ability and an increasing trend in adult mortality at doses greater than $25 \mathrm{~Gy}$.

High radiation doses also reduced the number of flying adults and increased the number of non-emerged pupae in the study performed by Rull et al. (2012), but no differences in tests of survival under stress were detected during their experiments. Recently, GallardoOrtiz et al. (2018) verified that males irradiated with 60 Gy were $98 \%$ sterile but achieved more matings than those irradiated at 70 or $80 \mathrm{~Gy}$. In the later study, dispersal and survival patterns were similar among the doses of 60,70 and 80 Gy.

Genetic differences within a species can affect insect radiosensitivity (Bakri et al., 2005a) and could help to explain part of the variation in results obtained by different authors. Further studies, however, are necessary to confirm this for different populations of $A$. obliqua.
The range of doses tested in this study reduced the fertility of males to less than $3 \%$ (i.e., sterility induction higher than $97 \%$ ), with an estimated $\mathrm{D}_{99}$ at 55.4 Gy. In our study gamma radiation did not affect negatively fly emergence, sex ratio and survival under stress. However, the dose of $80 \mathrm{~Gy}$ had a lower percentage of fliers than the 40 Gy treatment, which is in agreement with the results from Rull et al. (2012).

Therefore, considering the results from the present and previous studies, the dose of 60 Gy could be proposed as the best compromise between insect quality and sterility for the $A$. obliqua strain tested. The mean values for emergence and flying ability obtained at this dose are in accordance with the minimum acceptable values for this species $(73 \%$ and $61 \%$ respectively), according to the FAO/IAEA/USDA (2003, 2014).

Irradiation of the insects in the pupal stage affects the development of both the male and female reproductive organs and most fruit fly species are irradiated at the late pupal stage (Bakri et al., 2005a), which must receive an appropriate dose for complete female sterilization, since female flies are also released when bisexual strains are used. Furthermore, the differences in ovary size can be used to differentiate sterile flies from fertile (non-irradiated) in certain species (Guillen-Aguilar et al., 2016). In this study, the ovaries of the irradiated females ( 9 days old) showed significantly less length and width than those of the control treatment, but there was no difference between the doses evaluated (Figure 2).

Females are more radiosensitive than males for most tephritid species (Bakri et al., 2005a, b) and the results obtained here showed that, irrespective of the dose used (between 40 and $80 \mathrm{~Gy}$ ), the irradiation completely inhibited the reproductive development of the females, which did not present eggs in the ovaries. Similar results of ovarian atrophy were found by Nation (1974) and Walder and Calkins (1992) in A. suspensa. On the other hand, the results showed that the irradiation had the least obvious effect on testes, but affected especially width in comparison to the control (Figure 3). According to López-Guillén et al. (2008), the gamma radiation at a dose of $80 \mathrm{~Gy}$ affected the release of volatiles by laboratory-reared males of $A$. obliqua, which may affect their sexual activity and should be further investigated.

In general, quality control is essential to ensuring the success of a SIT program. However, as cited by Rull et al. (2012), certain parameters provide less informative guidance on fly performance. According to Cayol (2000), laboratory quality control tests are insufficient for accurately determining sterile male competitiveness. Therefore, further tests should be performed involving sterile male competitiveness and behavior for Brazilian populations of $A$. obliqua both in the laboratory as well as in field cages. 


\section{Conclusion}

It was possible to observe that the gamma radiation doses tested did not significantly affect the emergence, sex ratio nor survival under stress of a Brazilian population of Anastrepha obliqua. In its turn, as the doses increased, the gamma radiation affected the fertility of both males and females.

Irradiation of $A$. obliqua pupae $24 \mathrm{~h}$ before adult emergence at doses higher than 40 Gy resulted in ovarian atrophy in females, which were unable to lay eggs. In males, the testicles were less affected by increasing the radiation doses. As the atrophied ovaries are easily distinguished from non-irradiated ovaries after 9 days of adult life, the ovarian dissection technique could even be used to confirm the sterility of trapped females that are not adequately marked, a technique which has already been applied to the medfly (Guillen-Aguilar et al., 2016).

\section{Acknowledgments}

We thank the Conselho Nacional de Desenvolvimento Científico e Tecnológico /CNPq process 119865/2009-2) for financial support and for providing a scholarship to the first author.

\section{Authors' Contributions}

Conceptualization: Costa, K.Z.; Costa, M.L.Z.; Botteon, V.W.; Faggioni, K.M.; Costa, N.; Mastrangelo, T. Data acquisition: Costa, K.Z.; Costa, M.L.Z.; Faggioni, K.M.; Costa, N. Data analysis: Costa, K.Z.; Botteon, V.W.; Mastrangelo, T. Design of Methodology: Costa, K.Z.; Costa, M.L.Z.; Mastrangelo, T. Writing and editing: Costa, K.Z.; Costa, M.L.Z.; Botteon, V.W.; Faggioni, K.M.; Costa, N.; Mastrangelo, T.

\section{References}

Allinghi, A.; Calcagno, G.; Petit-Marty, N.; Gomez Cendra, P.; Segura, D.; Vera, T.; Cladera, J.; Gramajo, C.; Willink, E.; Vilardi, J.C. 2007. Compatibility and competitiveness of a laboratory strain of Anastrepha fraterculus (Diptera: Tephritidae) after irradiation treatment. Florida Entomologist 90: 27-32.

Bakri, A.; Mehta, K.; Lance, D.R. 2005a. Sterilizing insects with ionizing radiation. p. 233-269. In: Dyck, V.A.; Hendrichs, J.; Robinson, A.S., eds. Sterile insect technique: principles and practice in area-wide integrated pest management. Springer, Dordrecht, The Netherlands.

Bakri, A.; Heather, N.; Hendrichs, J.; Ferris, I. 2005b. Fifty years of radiation biology in entomology: lessons learned from IDIDAS. Annals of the Entomological Society of America 98: 1-12.

Cáceres, C.; Hendrichs, J.; Vreysen, M.J. 2014. Development and improvement of rearing techniques for fruit flies (Diptera: Tephritidae) of economic importance. International Journal of Tropical Insect Science 34: S1-S12.
Calkins, C.O.; Parker, A.G. 2005. Sterile insect quality. p. 269-296. In: Dyck, V.A.; Hendrichs, J.; Robinson, A.S., eds. Sterile insect technique: principles and practice in area-wide integrated pest management. Springer, Dordrecht, The Netherlands.

Castañeda, M.R.; Selivon, D.; Hernández-Ortiz, V.; Soto, A.; Canal, N.A. 2015. Morphometric divergence in populations of Anastrepha obliqua (Diptera, Tephritidae) from Colombia and some Neotropical locations. ZooKeys 540: 61-81.

Cayol, J.P. 2000. Changes in sexual behavior and life history traits of tephritid species caused by mass-rearing processes. p. 843860. In: Aluja, M.; Norrbom, A.L., eds. Fruit flies (Tephritidae) phylogeny and evolution of behavior. CRC Press, Boca Raton, FL, USA.

Dominiak, B.C.; Fanson, B.G.; Collins, S.R.; Taylor, P.W. 2014. Automated locomotor activity monitoring as a quality control assay for mass reared tephritid flies. Pest Management Science 70: 304-309.

Fisher, K. 1997. Irradiation effects in air and in nitrogen on Mediterranean fruit fly (Diptera: Tephritidae) pupae in western Australia. Journal of Economic Entomology 90: 1609-1614.

Food and Agriculture Organization [FAO]. 2003. Manual for Product Quality Control and Shipping Procedures for Sterile Mass-Reared Tephritid Fruit Flies, Version 5.0. FAO/IAEA/ USDA, Vienna, Austria.

Food and Agriculture Organization [FAO]. 2014. Product Quality Control for Sterile Mass-Reared and Released Tephritid Fruit Flies, Version 6.0. FAO/IAEA/USDA, Vienna, Austria.

Fricke, H.; Hart, E.J. 1966. Chemical dosimetry. v. 2. In: Attix, F.H.; Raesch, W.C., eds. Radiation dosimetry. Academic Press, New York, NY, USA.

Fu, L.; Li, Z.H.; Huang, G.S.; Wu, X.X.; Ni, W.L.; Qü, W.W. 2014. The current and future potential geographic range of West Indian fruit fly, Anastrepha obliqua (Diptera: Tephritidae). Insect Science 21: 234-244.

Gallardo-Ortiz, U.; Pérez-Staples, D.; Liedo, P.; Toledo, J. 2018. Sexual competitiveness, field survival, and dispersal of Anastrepha obliqua (Diptera: Tephritidae) fruit flies irradiated at different doses. Journal of Economic Entomology 111: 761-769.

Guillen-Aguilar, J.C.; López-Muñoz, L.; Pérez-Espinoza, E.; LópezVillalobos, E.F.; Marroquín-Solórzano, V.H.; Dominguez-Ventura, J.D.; Recinos-Castillo, E.G. 2016. Manual to Differentiate Wild Mediterranean Fruit Flies Ceratitis capitata (Wied.) from NonIrradiated (Fertile) and Irradiated (Sterile) Vienna Temperature Sensitive Lethal Strain Flies. IAEA, Vienna, Austria.

Hendrichs, J.; Robinson, A.S.; Cayol, J.P.; Erkenlin, W. 2002. Medfly area-wide Sterile Insect Technique programs for prevention, suppression or eradication: the importance of mating behavior studies. Florida Entomologist 85: 1-13.

López-Guillén, G.; Cruz-López, L.; Malo, E.A.; GonzálezHernández, H.; Cazares, C.L.; López-Collado, J.; Toledo, J.; Rojas, J.C. 2008. Factors influencing the release of volatiles in Anastrepha obliqua males (Diptera: Tephritidae). Environmental Entomology 37: 876-882.

Malavasi, A.; Zucchi, R.A. 2000. Fruit Flies of Economic Importance in Brazil: Basic and Applied Recognition. = Moscas-das-Frutas de Importância Econômica no Brasil: Reconhecimento Básico e Aplicado. Holos, Ribeirão Preto, SP, Brazil (in Portuguese). 
Mastrangelo, T.; Parker, A.G.; Jessup, A.; Pereira, R.; OrozcoDávila, D.; Islam, A.; Dammalage, T.; Walder, J.M.M. 2010. A new generation of $\mathrm{X}$ ray irradiators for insect sterilization. Journal of Economic Entomology 103: 85-94.

Nation, J.L. 1974. The structure and development of two sex specific glands in male Caribbean fruit flies. Annals of the Entomological Society of America 67: 731-734.

Orozco-Dávila, D.; Quintero, L.; Hernández, E.; Solís, E.; Artiaga, T.; Hernández, R.; Ortega, C.; Montoya, P. 2017. Mass rearing and sterile insect releases for the control of Anastrepha spp. pests in Mexico: a review. Entomologia Experimentalis et Applicata 176-187.

Parker, A.G. 2005. Mass-rearing for sterile insect release. p. 209-232. In: Dyck, V.A.; Hendrichs, J.; Robinson, A.S., eds. Sterile insect technique: principles and practice in areawide integrated pest management. Springer, Dordrecht, The Netherlands.

Ruíz-Arce, R.; Barr, N.; Owen, C.L.; Thomas, D.B.; McPheron, B.A. 2012. Phylogeography of Anastrepha obliqua inferred with mtDNA sequencing. Journal of Economic Entomology 105: 2147-2160.

Rull, J.; Diaz-Fleischer, F; Arredondo, J. 2007. Irradiation of Anastrepha ludens (Diptera: Tephritidae) revisited: optimizing sterility induction. Journal of Economic Entomology 100: 11531159.

Rull, J.; Birke, A.; Ortega, R.; Montoya, P.; López, L. 2012. Quantity and safety vs. quality and performance: conflicting interests during mass rearing and transport affect the efficiency of Sterile Insect Technique programs. Entomologia Experimentalis et Applicata 142: 78-86.
Salles, L.A.B. 1992. Rearing methodology of Anastrepha fraterculus (Wied, 1830) (Diptera: Tephritidae) on artificial diet in laboratory = Metodologia de criação de Anastrepha fraterculus (Wied, 1830) (Diptera: Tephritidae) em dieta artificial em laboratório. Anais da Sociedade Entomológica do Brasil 21: 479-486 (in Portuguese).

Smith-Caldas, M.R.B.; McPheron, B.A.; Silva, J.G.; Zucchi, R.A. 2001. Phylogenetic relationships among species of the fraterculus group (Anastrepha: Diptera: Tephritidae) inferred from DNA sequences of mitochondrial Cytochrome Oxidase I. Neotropical Entomology 30: 565-573.

Sokal, R.R.; Rohlf, F.J. 1981. Biometry. 2ed. W.H. Freeman, New York, NY, USA.

Toledo, A.J. 1993. Optimum dosage for irradiating Anastrepha obliqua pupae to obtain highly competitive sterile adults. p. 301-304. In: Aluja, M.; Liedo, P., eds. Fruit flies: biology and management. Springer, New York, NY, USA.

Toledo, J.; Rull, J.; Oropeza, A.; Hernández, E.; Liedo, P. 2004. Irradiation of Anastrepha obliqua (Diptera: Tephritidae) revisited: optimizing sterility induction. Journal of Economic Entomology 97: 383-389.

Walder, J.M.M.; Calkins, C.O. 1992. Gamma radiation effects on ovarian development of the Caribbean fruit fly, Anastrepha suspensa (Loew) (Diptera: Tephritidae), and its relationship to sterile fly identification. Florida Entomologist 7: 267-271.

Walder, J.M.M.; Morelli, R.; Costa, K.Z.; Faggioni, K.M.; Sanches, P.A.; Paranhos, B.A.J.; Bento, J.M.S.; Costa, M.L.Z. 2014. Large scale artificial rearing of Anastrepha sp.1 aff. fraterculus (Diptera: Tephritidae) in Brazil. Scientia Agricola 71: 281-286. 